\title{
Standardization and Professional Knowledge in Integration Work
}

\author{
Thomas Winman \\ School of Business, Economics and IT, University West, Sweden \\ Received April 19, 2021; Revised June 12, 2021; Accepted July 19, 2021
}

\section{Cite This Paper in the following Citation Styles}

(a): [1] Thomas Winman, "Standardization and Professional Knowledge in Integration Work," International Journal of Social Work and Human Services Practice, Vol. 8, No. 2, pp. 17 - 26, 2021. DOI: 10.13189/ijrh.2021.080201.

(b): Thomas Winman (2021). Standardization and Professional Knowledge in Integration Work. International Journal of Social Work and Human Services Practice, 8(2), 17 - 26. DOI: 10.13189/ijrh.2021.080201.

Copyright $(2021$ by authors, all rights reserved. Authors agree that this article remains permanently open access under the terms of the Creative Commons Attribution License 4.0 International License

\begin{abstract}
Since the 1970s, the government in Sweden has developed many activities aimed at facilitating immigrants' integration processes and their sense of belonging; one such activity that emerged in the 2010s is civic orientation. This activity is characterized by a high degree of standardization of both processes and content. The intention is for local activities and participants to adjust to general levels and standards. But even though standards can be seen as a solution for a set of problems, one must consider that standards do not perform any tasks by themselves; their functions depend on organizational routines, resources available, and staff members' use of the standards. Therefore, one must consider how integration workers handle standards and how they bridge standards of routines and procedures with participants, immigrants, responses, and needs. The interest in this study concerns how such a dilemma intervenes at the local level and what it means for professional knowledge and autonomy. This study takes place at an integration unit in Sweden where integration workers meet in workshops to interpret standards and find ways to adapt them to local needs. The results show how cultural and pedagogical awareness form the basis for professional knowledge and how this also creates a space for action but also how standards form a structure through which expectations and demands are understood and form arguments and interaction patterns.
\end{abstract}

Keywords Standardization, Integration Work, Professional Knowledge, Social Work, Migration

\section{Introduction}

Over the last few decades, there have been many debates and several studies that focused on immigrants' integration into societies. Concerns have shifted from multiculturalism to marginalization, and from identity processes to the labor market, but only a few have focused on integration activities, actual performance, and learning practices. Social work, and in particular the integration sector, is under strong and increasing pressure to collaborate and coordinate more efficiently across geographical, institutional, disciplinary, and professional boundaries; this is argued to be a way to reduce uncertainty and enhance legitimacy for human service organizations, which have been experiencing an ongoing discussion regarding whether increased standardization enhances or reduces professionalism.

There is a trend towards standardizing all social work, including integration work, and consequently, many manuals have emerged to prescribe actions; therefore, as Giddens (1990) put it, standardization is a way of controlling activities and ensuring both performance and content.

The intention of standardization is for local activities and integration workers to adjust to a general level or standard for integration work. However, since people must act with regard to local activities, there might be a dilemma when local needs meet general standards. The aim of this study is to scrutinize how integration workers bridge the gap between general standards and local needs, which implies an interest in standardized processes and content structures - in other words, this study concerns 
how integration is carried out and how the information of the standards is understood. More precisely, the aim of this study is to scrutinize the ways in which such standardization intervenes in how integration workers understand the information of the standards to bridge the gap between standards and local needs. To these ends, observations took place at monthly workshops for integration workers at an integration unit in Sweden.

\section{Immigration to Sweden}

Since the Second World War, Sweden has been an immigrant country (Byström \& Frohnert, 2017). The causes of migration have changed over time. Between 1950 and 1970, the high-speed Swedish economy and the lack of a labor force encouraged many people to move to Sweden to find work. In the 1970s, the Swedish economy began to deteriorate and labor immigration fell sharply. Working lives changed, requiring higher levels of education and greater language skills, which made it more difficult for immigrants to compete for jobs. During the 1980s and 1990s, refugees constituted an increasing portion of migrants to Sweden (Byström \& Frohnert, 2017; Winman \& Westerlind, 2019).

In the mid-90s, many people came to Sweden to escape the war in former Yugoslavia. Unrest in different parts of the world means that the flow of refugees from different countries continues today. In addition, many relatives of immigrants are moving to Sweden through so-called ancestry immigration.

The war in Syria has caused major refugee flows, and between 2014 and 2015, the number of asylum seekers in Europe doubled from 625,000 (Eurostat, 2015, p. 4) to more than 1.2 million (Eurostat, 2017). The situation in Sweden was similar, increasing from about 60,000 migrants per year to roughly 163,000 migrants per year in 2015 (SCB, 2019). Although migration to Sweden decreased to 116,000 people in 2019 , this figure is still larger than before 2014 (SCB, 2019).

Migrants are heterogeneous, with broad backgrounds, different life conditions, and various personal characteristics (Westerlind \& Winman, 2015). Various figures use differing terminology in the public debate, which can cause confusion. Most people seeking to emigrate to Sweden today are refugees. The term "refugee," according to the Geneva Convention (1951), includes people who are forced to flee because of war or due to persecution on account of war, race, nationality, sexual orientation, religion, or political opinion.

When a refugee arrives in Sweden, it concerns asylum, and such a case is processed by the Migration Board. While an application is being processed, the person is considered an asylum seeker but is not registered in Sweden and is therefore not included in the national population. When a residence permit has been granted, the person is registered as an immigrant, like anyone born in another country. However, the term immigrant is a general term that lacks a precise definition, and it does not really say anything about the country of birth, background, family relationship, language, education, or health status of a person.

When a person is integrated into society, that person is presumed to be an active citizen. Integration is a concept that has been addressed in many ways and often involves both social structure and individual behavior (Heckmann \& Schnapper, eds., 2016). The structural component of integration incorporates a dimension where individuals participate in formal organizations and activities to seek agency, such as in politics, education, or labor. To support the integration of immigrants into society, a variety of government-supported activities have emerged that aim to facilitate immigrants' integration processes and their sense of belonging (Gebhardt, 2016). One municipality integration activity in Sweden is civic orientation, and the target group for civic orientation includes all persons who migrated to Sweden and settled in the municipality, regardless of origin, background, or time of origin(SFS 2010:1138).

In Sweden, civic orientation is a 60 -hour integration program directed at immigrants with a residence permit who have joined the establishment program from the Swedish Public Employment Service and who are family immigrants, which usually means the spouse, cohabitant, or child of someone who lives in Sweden (SFS 2010:1138). Other types of family members who may apply are parents with children in Sweden, those planning to marry someone in Sweden (fiancées/fiancés), foster children, and full siblings. The regulation (SFS 2010:1138) states that the purpose of civic orientation is to facilitate the integration of new arrivals into the work and life of the community by providing a basic understanding of Swedish society and by forming a basis for further knowledge acquisition. Civic orientation provides immigrants with information about the following:

(1) human rights and fundamental democratic values,

(2) an individual's rights and obligations in general,

(3) how society is organized, and

(4) practical everyday life.

Furthermore, one goal of civic orientation is to ensure a certain national standard in terms of form and content. The program is delivered in an immigrant's native language, so groups are categorized by language. Generally, a new class starts when there is a full group (i.e., 15-20 people). If a participant misses one session, the material can be made up the next time the program is given, since the program is highly structured.

Civic orientation, like many educational activities, is characterized by a high degree of standardization, where processes and actions are highly structured on a general level. Civic orientation is similar to other standardized areas such as healthcare (Winman, Säljö \& Rystedt, 2012) 
in that standards are seen as solving problems discovered at local levels.

Other scholars (Masedo \& Masedo, 2009; Munro, 2011) have claimed that the introduction of standardization is a lack of trust that, in the long run, risks decreasing professional knowledge. Moreover, standardization, routinization, the fragmentation of work, and the loss of discretion, for example, can lead to deprofessionalization.

Thus, considering different actors' perspectives, inherent tensions seem to exist between an authoritarian culture and the values of professional autonomy and a culture of casualness and correctness, where the question embraces an overall ethos of stability as opposed to individualism.

\section{Integration Work and Standardization}

Studies of communication and learning have focused on standard procedures in the provision of adequate and satisfactory learning in which participants can be involved and assume responsibility for decisions (Harford, 2010; Bates, et al., 2019, McInerney, 2019). Some studies (Fortunato, 2017) have also illustrated the tension between standards and freedom in terms of what was highlighted, and, thus, considered relevant to pay attention to. The observations referred to above suggest some interesting dilemmas for integration (and other contexts); no standardized procedure can be complete, neutral, and relevant for all legitimate purposes. A standardized procedure must be selective and focus on what, according to some criteria and human interests, is considered relevant and significant to attend to in a particular practice.

In Sweden, standardized procedures have existed in different ways in almost all governmental integration activities since the 1970s. Nevertheless, the intention of integration activities is to provide individually adjusted support for immigrants so they can integrate into an unfamiliar society. Previously, integration activities were performed in different ways in different municipalities. A governmental reaction to what was considered unsafe and varying conditions was to implement a more uniform and standardized integration policy, regarding both process and content (SOU 2010:16; SFS 2010:1138).

\section{Standards and Dilemmas}

Some municipal bureaucrats in Sweden and Europe have begun pushing for standardized classes with standardized texts for integration work with immigrants (SFS 2010:1138; Åberg, 2020). Of course, such a proposal has certain merits. First, there is some general content that is most likely needed for most people moving to another country. This can be information about the immigration process and gaining citizenship, among other things, and standardization can help ensure that such content is provided for everyone and in a proper way. Standardized performance can also ensure that immigrants are prepared for such information and that it can be dealt with afterwards. Second, most municipalities have a general curriculum that is supposed to provide core integration. As with education for the majority, standardizing such a curriculum can help ensure that participants receive the necessary knowledge. Third, having a standardized curriculum will simplify things for integration workers and the organizers of integration work.

Despite these merits, this striving for homogeneity and standardized content has serious flaws. First, there is the matter of pragmatic and individual freedom. One critical aspect of the integration system is that the integration workers need to have a degree of autonomy, and this includes the right to select the material that will be taught. Obviously, integration workers need to abide by certain national regulations and expectations, but as long as an integration worker is doing a competent job, there seems little reason to take away such freedom of choice. Second, immigrants will most likely seek support and help that corresponds to their specific needs and interests; hence, standardizing the curriculum also restricts their freedom of choice in this matter. Third, some organizers write textbooks, and, therefore, there is the potential for a conflict of interest. For example, if some ethnic or religious groups have norms that conflict with the norms of the majority, some authors might highlight the norm of the majority in the standard text, which might erase or dismiss the religious/ethical norms. Fourth, each integration worker most likely has their own style and strengths and, therefore, prefers to use texts and other resources that match these qualities. For example, one integration worker might be well versed in varieties of education or democracy and hence select texts with more content in that area. Another integration worker might prefer a more informal approach to logic than another and so use tools that are more informal (and perhaps more interesting for participants). Fifth, if someone is qualified to orient a group of immigrants, then that person should be qualified to select suitable tools and texts. If this is not the case, then standardization will not really solve the problem.

In a standardized scenario, an incompetent person performs poorly while trying to follow a standard plan. While this might be somewhat better than an incompetent person following their own incompetent plan, it would still be a serious problem. This is analogous to saying that the solution to bad drivers getting into accidents is to make sure that everyone drives the same car, which would not solve the true problem. The solution is to replace someone who is incompetent with someone who can do 
the job properly or training the person. However, integration workers must competently provide cultural interpretation that immigrants need.

Türegün (2013) as well as Nash, Wong, and Trlin (2006) have stated that integration work is a new practice that requires its own forms of knowledge, practice, and values for workers to be skilled and make professional ethical judgements. But what is professional knowledge, and how does it relate to this study? Muzio and Kirkpatrick (2011) and Hopwood (2017) have considered professionals to be people in a collective setting who develop approaches, values, and strategies. The relation between professional knowledge and standardization in institutional practice is a central issue in this article; in this study, knowledge relates to integration workers' familiarity with subjects according to local standards, needs, and presumptions. On a general level, one can say that professional knowledge is a prerequisite for competent acting, which is valued in these situations, so knowledge is also the ability to participate in an integration activity.

From an epistemological perspective, knowledge is embedded in activities and, even though one can argue that knowledge is personal, it is also manifested and shared between people during activities. Therefore, integration workers need to express themselves in ways that are intelligible to others; otherwise, the risk increases, and the work will lack sense. This is consistent with Beyea (1999), who argued that even though professionals act and speak through scientific and administrative institutionalized categories that are often upheld and carried out through standards, there needs to be a mutual understanding about the meaning of standards - what they represent and how they can be handled.

\section{The Setting}

This study took place in a midsized municipality in Sweden in 2018, and the unit provided civic orientation for about 1,200 immigrants between 2016 and 2018. The amount of people who participate in civic orientation depends on how many people immigrate to Sweden and settle in that city. This means that the unit must constantly adapt both to the number of immigrants and to the place of emigration since civic orientation must be delivered in an immigrant's native language. To comply with these regulations, hourly integration workers have been hired for civic orientation.

To be able to handle changing needs and conditions, the unit does not have a permanent team of integration workers, and the team varies organically. There are generally formulated competence criteria when recruiting integration workers, and the minimum requirement is that they have both linguistic and cultural knowledge as well as basic pedagogical abilities. It is also desirable for them to be knowledgeable about the structure of Swedish society and the various social structures that are important to citizens. In practice, this means that the integration worker preferably has lived in the same country as the immigrants and has experienced living in Sweden for several years. This kind of double cultural and societal knowledge is recognized as important to understand the immigrants' needs and expectations. Those who have a pedagogical education or leadership experience from being, for example, a sports trainer is considered to have the basic pedagogical competence required.

According to a 2015 survey by the county government (Länsstyrelserna, 2015), the municipalities, which employed the integration workers, stated that they were aware that they have precarious employment conditions, such as hourly employment, which means that the turnover among the integration workers is high in many municipalities. Several municipalities expressed concern about future opportunities to recruit and retain competent employees. When new employees constantly need to be recruited and trained, integration quality may suffer. Although the municipalities recognized a need to offer better employment conditions, it is made more difficult by the fact that assignments within civic orientation often do not suffice for full-time services. In addition, the needs of language competence vary as languages among the target group change.

These components are also the focus of various continuing education programs (which are very few) and workshops organized by the unit each month. These workshops are three hours long and occur in the same place as civic orientation. Between eight and ten integration workers usually participate, along with two to three people from management and administration. During the first hour, management and administration usually inform everyone of what will happen and remind them of routines that must be followed or forms that need to be filled in. They also talk about the migration flow and what the demand for civic orientation is expected to look like in the near future. Integration workers raise general issues, such as reporting attendance.

The integration workers then divide into groups to start the workshops, where they discuss the challenges and dilemmas encountered at work. Management and administration remain in the building to provide assistance if there are issues that concern them, but otherwise these workshops are entirely driven by the needs of the integration workers, and they also provide an arena where people have the opportunity to learn from and with each other.

\section{Data Collection}

There were eight integration workers who attended the workshops when data collection took place. After being provided with the details of the study, all integration 
workers agreed to participate in the study. None worked full-time in civic orientation, but all were regarded by management as experienced, as the least experienced had held at least seven civic orientation courses while the most experienced had held 17 civic orientation courses (see Table 1 below) at the first workshop. The same integration workers were at both workshops, and there were five weeks between the workshops.

Table 1. Description of the integration workers that attended the observed workshops

\begin{tabular}{ccccc}
\hline $\begin{array}{c}\text { Integration } \\
\text { worker }\end{array}$ & Sex & $\begin{array}{c}\text { Education } \\
\text { Level }\end{array}$ & $\begin{array}{c}\text { Mother } \\
\text { tongue }\end{array}$ & $\begin{array}{c}\text { Number } \\
\text { of } \\
\text { courses } \\
\text { taught }\end{array}$ \\
\hline 1 & Male & University & Arabic & 13 \\
\hline 2 & Female & $\begin{array}{c}\text { High } \\
\text { school }\end{array}$ & Arabic & 7 \\
\hline 3 & Male & $\begin{array}{c}\text { Secondary } \\
\text { school }\end{array}$ & Somali & 17 \\
\hline 4 & Male & $\begin{array}{c}\text { High } \\
\text { school }\end{array}$ & Arabic & 16 \\
\hline 6 & Male & $\begin{array}{c}\text { High } \\
\text { school }\end{array}$ & Tigrinya & 8 \\
\hline 7 & Female & $\begin{array}{c}\text { Secondary } \\
\text { school }\end{array}$ & English & 9 \\
\hline 8 & Male & University & Arabic & 7 \\
\hline
\end{tabular}

In total, two workshops for integration workers from a midsized municipality in Sweden were observed in 2018. There were four integration workers in each workshop. Periodic workshops at the department were considered crucial, as they focused on aspects of quality related to the standards and understanding of their work.

The purpose of this data was to understand the overall expectations, norms, and activities present when preparing, organizing, and performing the work. Moreover, the data were intended to reveal pre-established patterns related to objects, purposes, goals, values, and procedures "already-in-place", which can be understood as elements of knowledge that have emerged through history to which the integration workers orient themselves. More precisely, the purpose of the field work was to scrutinize how the information in the standards is understood and if, where, and how integration workers bridge the gap between standards and local needs.

Each workshop lasted for three hours and was based on extensive field-based observations and audio recordings. The observed activities focused on how integration workers handled and bridged dilemmas between the standardized material and the local needs. Field notes were written in close conjunction with the observations, and the field notes included the names of participants, the aims of the activities, and the topics addressed. Immediate interpretations of what the participants addressed as important were documented. These notes have been used as complementary data to support and illustrate the interpretations. All field notes and audio recordings were transcribed within two days.

\section{Analysis}

All data, including field notes from observations and transcriptions of audio recordings, formed the basis for an endogenous analysis of the integration workers' perspectives embedded in their practices. The field notes assisted with corroborating an understanding of the overall workflow, the ways in which the integration workers interacted with each other, how workers framed their work, and how workers oriented themselves to challenges. Field notes were also used to see how standards were integrated into the activities when relating information about immigrants with the delivery of the integration work.

The analysis also involved repeatedly listening to the audio recordings of the workshops and reading through the transcriptions. Re-readings and notes in the margin of the transcriptions (Hammersly \& Atkinson, 1995; Silverman, 2000) aided an understanding of the relationship between arguments and standards in the process; this study focused on structures and interactional patterns in the workshops. Initially, patterns were discerned between local needs and the impact of standards on typical reconstructions of cases.

\section{Results}

The results show that the value structure of standardizing integration work at the unit emanated from a management-based view of immigrants' needs, which determined not only what immigrants required but also the routines of when and how they need their requirements. The management-based structure of how to perform integration work is characterized by dividing complex societal pictures, values, norms, and presumptions into different categories and sub-categories. As seen in Excerpt 1 below, this uniform organization contributes to locally shared knowledge among the integration workers about the process and content of the integration work. At the same time, it subsidizes a uniform linguistic usage, and one could say that through the development of commonly shared terms, an integration work language emerges.

\section{Excerpt 1}

Integration worker 1: Yes, yes, it is always difficult to teach them about society and democracy. Especially when it comes to different voting systems like in the municipality, the region, and parliament.

Integration worker 2: It is not that strange because they come from a dictatorship. 
Integration worker 1: But that is why it is good to follow this order (pointing to the teaching material) so that you start by telling them what we mean by democracy before going into the different levels or parties.

Integration worker 2: Yes, I think so, too.

It is clear that these workers identified problems from their experiences. They know that they must teach immigrants about complex issues. They also point out that a participant's background can make learning difficult, but they do not get bogged down by it. Instead of talking about how they may need to adapt the topics to their backgrounds, it instead becomes a quick observation before they return to discussing the order of the teaching material.

However, there is no doubt that legislation and the national policy in Sweden both offer and presuppose a high degree of standardization. As these results show, the integration workers related and adapted to the terminology of the standardized content in different ways.

\section{Excerpt 2}

Integration worker 1: But, I think you first have to explain parliament and government before discussing the democratic system.

Integration worker 2: I've tried that because some of the participants wanted it. But it was difficult to start there.

Integration worker 1: No, no.

Integration worker 3: But what, what do you mean when you say the democratic system?

Integration worker 1: But, it says it here. [Points to the book.] Just follow what it says. That is what the democratic system is.

As seen in Excerpt 2, standardization unconsciously structures the relation within and between different items and topics, which significantly affects the integration workers' understanding of what is expected, desirable, and correct. It is also important to remember that the standards, standardized terminology, and upheld structures are not vital-rather, it is the integration workers' use of them that gives life to the standards. Therefore, when integration workers use the standards, they must act according to the standardized terminology and structure; thus, the standards also constrain the individuals' understanding of the situation and procedures This is consistent with the view of Timmermans and Epstein (2010) who see standardization almost as a presumption of local adaption and adjustment.

\section{Excerpt 3}

Integration worker 1: I think what it says here is perfect. [Points to the book.] "The elected politicians represent the voters and therefore the system is called representative democracy." That, I think, it's easy to explain how it works. I mean, it's just like home. The elders represent the village or clan when it is a larger council. Everyone recognizes and understands, but if I just say representative democracy, they don't understand. I have to explain that.

Integration worker 3: Yes, yes, smart. You have to do it so they understand. It is not enough to just tell them how it is. But that's only one part of a democracy.

Integration worker 1: What do you mean? It's about the way it works.

Integration worker 3: I mean that with elections, everyone has the right to vote on who should represent them. This means, of course, that the elderly do not decide for the people, but the contrary.

Excerpt 3 demonstrates the argument by Knorr-Cetina (1981) that staff are practical reasoners preoccupied with trying to make things work, meaning that they have to determine what the standards mean for them in every situation. Thus, even if someone argues that a high degree of standardization impedes autonomy, such meaning-making can also be considered a vital aspect of professional knowledge. As seen in Excerpt 3, the integration workers identified themselves with their work, trying to make things work is a kind of bonding, both with the organization as a whole, with their colleagues, and with their integration into the work itself. This is in line with Engel (1970), who defined personal autonomy as the "freedom to conduct tangential work activities in a normative manner in accordance with one's own discretion." Additionally, work-related autonomy was defined as the "freedom to practice his profession in accordance with his training." This means that a person links work and organizational behaviors, norms, and attitudes with their own interests, values, norms, and behaviors.

From this, it follows that standards constitute and set perspectives if they transform the staff's understanding of the problem and how the problem should be handled. At the integration unit where this study took place, categories in the standardized texts functioned as stabilizing items that made expectations of knowledge and processes recognizable for the integration workers. In other words, the integration workers' thinking can be seen as being shaped and transformed by institutional categories as it becomes a part of such settings (Mehan et al., 1986). This emphasizes that reaching a mutual understanding of "how to get things to work" takes place in a discursive practice that presupposes knowledge of how to structure, re-construct, and express information.

It was clearly stated that the intention of the standards for the integration unit was to include and provide enough information for carrying out adequate and proper integration work. Such assumptions, though, may be questionable, since what happens to staff in face-to-face dialogues with immigrants when they are discussing the meaning of the information in the standards is not solely 
an issue of the transmission of information. Instead, the gap between formal information and its practical use can be understood from the fact that there is, necessarily, a lack of fit between the systems, signs, and actions, as Jensen (2006) put it. In Excerpt 3, the integration workers discuss how to overcome such gaps and their professional knowledge about the immigrants, and their cultures of origin become an important resource. Moreover, local needs simply cannot be anticipated for all practical purposes and all possible participants. The transformational processes involved in bridging the gap between the formal and the practical concerns in integration work rely on extensive-but often unnoticed-proficient performance.

\section{Excerpt 4}

Integration worker 6: This is interesting - in my home language, there is no word for leisure, not like in Swedish.

Integration worker 7: No, not in mine either, but how do you relate to it then?

Integration worker 6: What do you mean by relate?

Integration worker 8: Yes, yes, I usually... So, I mean, I usually start with leisure, just like in the book, because when I know they [the immigrants] understand it, then it is easier to go to the next step in the book-this [points to the book] - by association.

Integration worker 6: I do the same, but I also have to explain what association is, for there is neither of them in that way in their home country.

Integration worker 7: Precisely, that's what you have to do because otherwise it will mean nothing to them [the immigrants].

As seen in Excerpt 4, the power of the standards also becomes evident since their structure, categorizations, and classifications seem to construct and value skills, knowledge, and items. This indicates that standards uphold, or at least indicate, a certain logic that prescribes what the knowledge is or what is relevant. The standards function not only as organizational tools for structuring knowledge or information but also as powerful tools that monitor organizational procedures and even the whole organization. Standards carry their own ontology and may help the user with activities, such as dialogues or decision-making. That, however, presumes that the integration worker has a diversity lens that allows them to move beyond the stereotypical framing of immigrants under the guise of what van der Haar (2009, p. 146) called "ascribed collective culture."

\section{Excerpt 5}

Integration worker 5: Yes, I can't understand why you should go into how to start uniting at all. It would have been much better to have fewer subjects to talk about and instead focus more on one or two. Now, there are so many different things that no one remembers anything.

Integration worker 7: Ha ha, but you should always think a lot. I'm not saying that you are wrong, but it may be that they [the immigrants] still understand that they can start or join a cultural association or that their children are members on the same terms as everyone else if they start playing football.

Excerpt 5 shows that not all teachers feel the same way about the impact of standardization on their autonomy. While some teachers feel that their hands are tied by the standardization, others argue that the standardized integration work and the use of terminology more or less function as what Star and Griesemer (1989) called boundary objects. This means that standardization gives them security and something to relate to. Its strength is in its power to transform understandings about content and expectations as well as in its ability to guide teaching procedures and routines in different situations. The staff work together in a unit where standardized understandings of content give them the power to translate information between people and contexts. But, as indicated by these results, boundary power is not something that standardization itself provides; the staff can use it to translate information. Therefore, it is reasonable to argue that its use brings standardization to life in such a manner that it becomes a boundary object.

From this point of view, boundary objects can be a tool for developing the staff's cultural sensitivity and incremental ability to meet the needs and expectations of immigrants; in the longer term, it can be used to develop culturally competent practice. However, what this competence more concretely means regarding self-awareness and autonomy remains largely unknown. That said, looking at the actual use of the standards exposes how staff act with confidence and assurance regarding the standardized terminology and structures. On the contrary, the results reveal that they do not unconditionally adopt an imagined recipe of logic that is built into the standards. Their assertiveness upholds that the standards are built on logic; therefore, their actions can be seen as manifesting distrust of local, alternative forms of organizing knowledge.

\section{Discussion}

It is seductively simple to, like Ponnert and Svensson (2016), assume that a high degree of standardization is equal to inadequate professional knowledge about integration work and that standards function in contrast to autonomy. Moreover, standardization is often emphasized as the reason that integration work agencies fail to provide ethnic minority clients, or newly arrived people, with equal chances in terms of their possibilities. Integration workers must act according to organizational norms and expectations but also in line with their own professional 
values.

However, the results show that standardization is not carried out of its own accord but in organizational contexts and by stakeholders, with intentions and expectations, who diffuse and adopt standardization and adapt to it for various reasons and with various levels of comprehension. As shown in Excerpt 2 ("Integration worker 2: I've tried that because some of the participants wanted it. But it was difficult to start there."), integration workers face both internal and external demands to become more effective in facilitating integration for immigrants. Previously, Sweden had varied practices and professional achievements, which was viewed as problematic since the content that immigrants received at civic orientation depended on where in the country they lived. Thus, standardization constructs uniformities across time and space. This contrasts those who view standardized assessment and social work in integration work as solely reflecting distrust in professionals and, thus, a breach in what is called the "professional contract" between the state and professionals (Ahlbäck Öberg et al., 2016).

As seen in Excerpt 4 ("Integration worker 7: Precisely, that's what you have to do because otherwise it will mean nothing to them [the immigrants]."), integration workers constantly grapple with how to help immigrants understand the standards and ways to make the content vivid and understandable. However, the integration workers did not feel that their professional capacity was challenged by the standards, and some even said that their capacity was enhanced. In a sense, using standards as an objective measure of performance-thereby clarifying the task-enhanced this group of integration workers' self-esteem; they were able to discuss their performance in light of the standards. Their concerns, generally summarized, regarded an increased need for individual explanations that required time not permitted by the schedule. Nevertheless, they found time, which can be characterized as creative and professional work performance.

In this analysis, one important difference between integration workers is how they view their work in relation to standards and autonomy and the extent to which they associate autonomy with professionalism. Some viewed autonomy over their work in the classroom as one of the most important aspects of their teaching, and when they perceived that their autonomy was undermined, they expressed dismay and even a desire to abandon teaching.

Integration workers' job satisfaction included autonomy, but workers valued it differently. The autonomy they appear to value has more to do with how they treat the individual immigrants than with the content they can teach in the classroom as professionals. The data from this study suggest that these integration workers never felt that they should be free to make all the curriculum decisions because they never had the chance to do so. Their work feels safe because it involves a high degree of standardization. The data presented in this paper show that staff may have different views regarding the importance of such autonomy versus standardization. They suggested that standardization either did not really influence their views of themselves as teachers or clarified their perception of tasks. This indicates that they value professional autonomy differently.

However, saying that they do not value autonomy may not entirely capture the reality of teaching for these people. The data indicate that they consider some areas of their work to be more open to autonomous decision-making. These integration workers desire autonomy so they can work in their own ways, including with regard to work schedules and increased work duties. Earlier views regarding "new" versus "old" professionalism suggested that new employees were willing to accept the new forms of work, such as standardization, in exchange for more responsibility and decision-making. However, this is not supported by data in this study. The everyday encounters with diversity, as embodied by the immigrants, can reinforce integration workers to be more sensitive to the relevance of their own work, meaning that they are reflexive and can be self-critical.

Sticking to manuals is an easy way for professional integration workers to adjust to organizational norms and demands that could support the development of a professionalism based on reflection in action and collegial authority; to do so demands a more solid collegial identity. But one risk with increased standardization, as shown in this study, is a given administrative "certainty" where some integration workers become comfortable with a standardized and administrative-based way of thinking, resulting in uncertainty when professional judgement is required.

Yet, empirically based knowledge of how professionals bridge the gap between standards and local needs lags remarkably behind. Little research is available about, for example, how immigrants' diversity is reflected in organizational arrangements and how it is perceived and understood by integration workers. Given this state of the literature, this study has explored three aspects of professional practice in which the lenses of standards and autonomically local knowledge raise distinctive insights and dilemmas: the ways of framing immigrants, the reception of diverse needs in integration work, and the everyday interactions between integration workers and immigrants.

\section{REFERENCES}

[1] Bates, J., Schrewe, B., Ellaway, R. H., Teunissen, P. W., \& Watling, C. (2019). Embracing standardisation and 
contextualisation in medical education. Medical education, $53(1), 15-24$.

[2] Beyea, S. C. (1999). Standardized language-making nursing practice count. AORN Journal, 70(5), 831-838.

[3] Byström, M., \& Frohnert, P. (2017). Invandringens historia: från" folkhemmet" til dagens Sverige. Delegationen för migrationsstudier (Delmi).

[4] Engel, G. V. (1970). Professional autonomy and bureaucratic organization. Administrative Science Quarterly, 15(1), 12-21.

[5] Eurostat (2017), "1.2 million first time asylum seekers registered in 2016", available at: https:/ec.europa.eu/eurostat/documents/2995521/7921609/ 3-16032017-BP-EN.pdf/e5fa98bb-5d9d-4297-9168-d07c6 $7 \mathrm{~d} 1 \mathrm{c} 9 \mathrm{e} 1$.

[6] Fortunato, M. W. (2017). Advancing educational diversity: antifragility, standardization, democracy, and a multitude of education options. Cultural Studies of Science Education, 12(1), 177-187.

[7] Gebhardt, D. (2016). When the state takes over: Civic integration programmes and the role of cities in immigrant integration. Journal of Ethnic and Migration Studies, 42(5), $742-758$.

[8] Geneva Convention (1951). The 1951 Refugee Convention. UNHCR, New York

[9] Giddens, A. (1990). The consequences of modernity. Cambridge: Polity Press.

[10] Hammersly, M., \& Atkinson, P. (1995). Ethnography, principles in practice. New York: Routledge.

[11] Harford, J. (2010). Teacher education policy in Ireland and the challenges of the twenty-first century. European Journal of Teacher Education, 33(4), 349-360.

[12] Heckmann, F., \& Schnapper, D. (Eds.). (2016). The integration of immigrants in European societies: National differences and trends of convergence (Vol. 7). Walter de Gruyter GmbH \& Co KG.

[13] Jensen, D. H. (2006). Responsive labor: A theology of work. Kentucky: Presbyterian Publishing Corp.

[14] Knorr-Cetina, K. D. (1981). The micro-sociological challenge of macro-sociology: Towards a reconstruction of social theory and methodology. In: Knorr-Cetina, K., A. V. Cicourel, (eds.) Advances in social theory and methodology: Toward an integration of micro- and macro-sociologies. Boston: Routledge \& Kegan Paul, pp. 1-47

[15] Länsstyrelserna (2015). Samhällsorientering för nyanlända - Länsstyrelsernas gemensamma redovisning. Göteborg, Sweden

[16] McInerney, S. A. D. (2019). A Study of Curriculum Customization in the Era of Standardization of Education. Doctoral dissertation, Seton Hall University.

[17] Macedo, S., \& Macedo, S. (2009). Diversity and distrust: Civic education in a multicultural democracy. Harvard University Press.

[18] Mehan, H., Hertweck, A., \& Meihls, J. L. (1986).
Handicapping the handicapped: Decision making in students' educational careers. Stanford University Press, Stanford.

[19] Munro, E. (2011). The Munro Review of Child Protection: Final Report. A Child-Centred System. Presented to Parliament by the Secretary of State for Education by Command of Her Majesty, May 2011.

[20] Muzio, D., \& Kirkpatrick, I. (2011). Introduction: Professions and organizations - A conceptual framework. Current Sociology, 59(4), 389-405.

[21] Nash, M., Wong, J., \& Trlin, A. (2006). Civic and social integration: A new field of social work practice with immigrants, refugees and asylum seekers. International Social Work, 49(3), 345-363.

[22] Ponnert, L., \& Svensson, K. (2016). Standardisation - The end of professional discretion? European Journal of Social Work, 19(3-4), 586-599.

[23] Reich, A., Rooney, D., \& Hopwood, N. (2017). Sociomaterial perspectives on work and learning: Sites of emergent learning. Journal of Workplace Learning, 29(7-8), 566-576.

[24] SCB (2016). Sveriges framtida befolkning 2016-2060 (Sweden's future population 2016-2060). Stockholm, Sweden.

[25] SCB (2019). Skilda världar? Det demografiskt delade Sverige. (Separate Worlds? The demographically divided Sweden). Stockholm, Sweden.

[26] SOU 2010:16 (2010). Sverige för nyanlända - Värden, välfärdsstat, vardagsliv. Delbetänkande från Utredningen om samhällsorientering för nyanlända invandrare. Fritzes förlag.

[27] SFS 2010:1138. (2010). Förordning om samhällsorientering för vissa nyanlända invandrare. Svensk författningssamling.

[28] Silverman, D. (2000). Doing qualitative research: A practical handbook. London: Sage.

[29] Star, S. L., \& Griesemer, J. R. (1989). Institutional ecology, translations' and boundary objects: Amateurs and professionals in Berkeley's Museum of Vertebrate Zoology, 1907-39. Social Studies of Science, 19(3), 387-420.

[30] Timmermans, S., \& Epstein, S. (2010). A world of standards but not a standard world: Toward a sociology of standards and standardization. Annual Review of Sociology, $36,69-89$.

[31] Türegün, A. (2013). Immigrant settlement work in Canada: Limits and possibilities for professionalization. Canadian Review of Sociology/Revue canadienne de sociologie, 50(4), 387-411.

[32] Van der Haar, G., van den Berg, D., \& Langen, E. (2009). Local government and the politics of peacebuilding and reconstruction in fragile states: Preliminary findings and discussion. Working paper, VNG/Network Peace Security and Development.

[33] Westerlind, M. \& Winman, T. (2015) Knowing in practice: The use of dialogue as a pedagogical method in integration 
work. Nordic Journal of Migration Research, 5(4), 168-176.

[34] Winman, T., \& Westerlind, M. (2019). Dimensions of professional knowledge. Social Work and Social Welfare, 1(1), 13-22.

[35] Winman, T., Säljö, R., \& Rystedt, H. (2012). Local knowing and the use of electronic patient records: Categories and continuity of health care. Health and Technology, 2(3), 185-196.

[36] Åberg, L. (2020). Standardiseringsarbetets kollektiva praktik. En studie om att kvalitetssäkra integrationssatsningen Samhällsorientering för nyanlända. Doctoral Dissertation, Gothenburg University. 